\title{
The Mouse Mutation Reeler Causes Increased Adhesion within a Subpopulation of Early Postmitotic Cortical Neurons
}

\author{
Raymond M. Hoffarth, Janice G. Johnston, Leslie A. Krushel, ${ }^{a}$ and Derek van der Kooy \\ Neurobiology Research Group, Department of Anatomy and Cell Biology, University of Toronto, Toronto, Ontario, \\ Canada M5S 1 A8
}

\begin{abstract}
Early postmitotic cortical neurons are mostly corticofugal projection neurons that take up positions in deep cortical laminae. Later postmitotic neurons are preferentially localized to superficial cortical laminae. In reeler mutant mice it appears that cortical laminar positions with respect to birthdate are reversed (Caviness, 1982). In a reanalysis of reeler lamination we found that early postmitotic cortical neurons labeled by embryonic day (E) 11-13 Injections of a birthdate marker, or by early postnatal day (PND) 2 retrograde labeling through their output projections, appear to take up positions both in the superficial and deep cortex. Neurons born on E11 and E12 are more likely to be situated superficially in the reeler cortex and neurons born on E13 are more likely to be situated in the deep reeler cortex. Many corticofugal projection neurons in the deep (but not superficial) reeler cortex either die or retract their axons before PND 21.
\end{abstract}

We hypothesize that the earliest postmitotic (E11-E12) of the early postmitotic reeler cortical neurons are overly adhesive and act as a barrier to later postmitotic migrating neurons. In vitro cortical aggregation cultures confirmed that early postmitotic (E12) reeler neurons are more adhesive than early postmitotic (E12) wild-type neurons or late postmitotic (E16) reeler or wild-type cortical neurons. We suggest that the moderate wild-type preferential adhesion of early postmitotic cortical neurons to each other helps deep and superficially fated lineages to form cortical laminae.

[Key words: cortical neurogenesis, reeler, cell migration, adhesion, corticofugal projections, cell death, axon retraction]

Neo-, or six-layered, cortex is a defining feature of mammalian forebrain architecture not shared by other vertebrates (MarinPadilla, 1978). In mice the entire complement of cortical neurons becomes postmitotic during the final $8 \mathrm{~d}$ of a $19 \mathrm{~d}$ gestation. Newly postmitotic immature neurons migrate radially away from the central lumen (ventricle) to form the cortical plate. Cortical neurogenesis in mammals occurs along a deep-superficial gradient: deep layer VI and V neurons are generated first, then layer IV neurons, and finally layer II/III neurons (Angevine and Sid-

\footnotetext{
Received Oct. 26, 1994; revised Feb. 13, 1995; accepted Feb. 15, 1995.

This work was supported by the Medical Research Council of Canada.

Correspondence should be addressed to Derek van der Kooy at the above address.

aPresent address: Department of Neurobiology, Scripps Research Institute, 10666 North Torrey Pines Road, La Jolla, CA 92037.

Copyright (C) 1995 Society for Neuroscience $0270-6474 / 95 / 154838-13 \$ 05.00 / 0$
}

man, 1961; Raedler and Raedler, 1978; Konig and Marty, 1981; Caviness, 1982; Smart and Smart, 1982; van der Kooy and Fishell, 1987; Miller and Nowakowski, 1988). As development proceeds, the later a neuron becomes postmitotic, then the farther it migrates away from the proliferative zone to take up a more superficial cortical position.

It remains unclear which mechanisms enable neurons fated to different layers to migrate through the embryonic milieu of neighboring cells, processes, and extracellular matrix to settle at an appropriate laminar position. Individual precursors in the proliferative zone often give rise to progeny all fated to reside within one of the deep or superficial laminae (Crandall and Herrup, 1990; Fishell et al., 1990; Krushel et al., 1993). On the basis of transplantation experiments McConnell and Kaznowski (1991) suggested that neurons decide their respective laminar fates only during their final division. However, these experiments also are open to interpretation in terms of differential survival of lineages fated to reside within deep or superficial cortical positions (van der Kooy, 1992). During prenatal development superficial and deep-layer neurons intermingle and contact each other in the cortical plate (Caviness and Rakic, 1978). Each class appears to act in homotypic fashion, segregating themselves according to birthdate to produce the laminar mammalian cortex. Mammalian deep and superficial cortical neurons also appear to be able to separate themselves in vitro on the basis of an adhesional hierarchy (Krushel and van der Kooy, 1993).

In mice homozygous for the reeler mutation (Falconer, 1951) the normal deep to superficial pattern of neurogenesis in cortex is apparently inverted, without affecting the appearance or number of any of the various classes of neocortical neurons (Sidman, 1968). Neuronal phenotypes corresponding to deep projection neurons in wild-type cortex (that become postmitotic early in neurogenesis) are at the top of the reeler cortex, while later postmitotic neurons settle toward the bottom (Sidman, 1968; Goffinet, 1979; Caviness, 1982).

We used both retrograde labeling of corticofugal projection neurons and birthdate markers in reeler $(r l / r l)$ mutant mice to analyze the cortical distributions of those neurons that would be fated to cortical deep-layer positions in wild-type mice. The results indicate that only the very earliest postmitotic [embryonic day (E) 11 and E12] of the early postmitotic reeler cortical neurons reside in superficial (ectopic) positions. The later postmitotic (E13) subpopulation of the early postmitotic reeler neurons ends up in a wild-type-like deep cortical position; both of the early postmitotic reeler subpopulations (deep and superficially located) contain corticofugal neurons. We hypothesized that the reeler mutation disrupts the ability of most postmitotic neurons 
to migrate past the earliest postmitotic neurons to more superficial positions. Using an in vitro neuronal adhesion assay (Krushel and van der Kooy, 1993), we tested for differences between reeler and wild-type animals in the adhesive characteristics of the early postmitotic neurons. Our findings suggest that the aberrant reeler cortical architecture results, at least in part, from a hypermorphic adhesion mechanism peculiar to the earliest postmitotic cortical neuron population, rendering them impermissive to the migration of later postmitotic cortical neurons. The majority of later postmitotic neurons are likely affected secondarily, only through their inability to migrate past the very earliest postmitotic population. The reeler mutation reveals that selective neuronal adhesion may be an important mechanism helping to segregate deep versus superficial cortical neuronal lineages to distinct laminae in wild-type mice.

\section{Methods and Materials}

Reeler mice. IIeterozygous $(r l l+)$ reeler (the Orléans allele on a BALB/C background) females were housed overnight with a homozygous $(r l / r l)$ reeler male. Females were examined at 9:00 A.M. for the presence of a vaginal plug and positive dams were then housed separately, and this day was taken to be E0. Littermates from these matings result in both heterozygous $(r l /+)$ and homozygous $(r l / r l)$ offspring. Given that reeler mice have a recessive autosomal (chromosome 5) mutation, only homozygous $(r / / r l)$ animals display the misaligned cortical (reeler) phenotype, while heterozygous $(r l /+)$ animals have apparently normal cortices and will be referred to here as heterozygous controls. The aggregation experiments required all homozygous $(\mathrm{rl} / \mathrm{rl})$ embryos, so homozygous $(r l / r l)$ females were housed overnight with homozygous $(r l / r l)$ males, while wild-type $(+/+)$ females were housed with wild-type $(+/+)$ males on the same days. The controls for the aggrcgation cxperiments were wild-type BALB/C mice also timed-bred according to the above procedure, and their embryos are referred to here as wild type.

Retrograde labeling of corticofugal neurons. Deep cortical projection neurons were retrogradely labeled (Fishell and van der Kooy, 1987) by microinjections of $0.2 \mu \mathrm{l}$ true blue (Sigma) into the cerebral peduncles (to selectively label layer V neurons), and in some animals layer VI neurons were labeled retrogradely using injections of $0.2 \mu \mathrm{l}$ diamidino yellow (Sigma) into the thalamus. Postnatal day (PND) 2 mouse pups were placed in a freezer $\left(-10^{\circ} \mathrm{C}\right)$ for cold anesthetization and PND 19 pups were anesthetized with sodium pentobarbital by intraperitoneal injection $(65 \mathrm{mg} / \mathrm{kg})$. Three types of microinjections were performed in which separate mouse pups from the same litters were (1) injected on PND 2 and sacrificed on PND $5(n=17),(2)$ injected on PND 2 and sacrificed on PND $21(n=6)$, or (3) injccted on PND 19 and sacrificed on PND $21(n=16)$. On the day of sacrifice pups were anesthetized with sodium pentobarbital and transcardially perfused with ice-cold $\left(4^{\circ} \mathrm{C}\right)$ paraformaldehyde $(4 \%)$. Brains were postfixed for $1 \mathrm{hr}$ afterward in paraformaldehyde $(4 \%)$, then overnight in paraformaldehyde $(4 \%)$ and sucrose $(30 \%)$. Cryostat coronal sections $(30 \mu \mathrm{m})$ were mounted on gelatin-coated slides and viewed under fluorescence illumination with a $360 \mathrm{~nm}$ filter. All the true blue retrogradely labeled neurons within each of 10 bins dividing up the cortex equally between pia and white matter were examined in sections through the somatic sensorimotor cortex of both heterozygous control $(r l /+)$ and homozygous $(r l)$ $r l$ ) littermates sacrificed on PND 5 and PND 21. The width of the cortical areas was $400 \mu \mathrm{m}$ and the height of the bins was the same for each bin within a section but changed across sections depending upon the expanded radial distances from white mattcr to pia (especially between pups sacrificed at PND 5 and PND 21). The total numbers of true blue labeled neurons within each of the 10 bins were expressed as percentages of the total numbers of labeled neurons within all 10 bins within a section. Counts were averaged from two separate and nonadjacent sections chosen from the same approximate level rostral to the crossing of the anterior commissure in each mouse.

$B r D U$ birthdating. Using injections of bromodeoxyuridine ( $\mathrm{BrDU})$ to label embryonic neurons in their last divisions before becoming postmitotic, we plotted the distribution of early postmitotic (presumptive deep layers V and VI) neurons in homozygous ( $r l / r l)$ and heterozygous $(r l /+)$ cortices at PND 21 and PND 5. Pregnant dams were injected with $\mathrm{BrDU}(140 \mathrm{mg} / \mathrm{kg})$ dissolved in $0.007 \% \mathrm{NaOH}$, either in the af- ternoon on E11 $(n=3)$, or in the morning on $\mathrm{E} 12(n=3)$ or $\mathrm{E} 13(n$ $=3$ ). Females gave birth to litters containing both heterozygous $(r l /+)$ and homozygous $(r l / r l)$ reeler pups. Heterozygous and homozygous reeler pups were sacrificed on PND 5 and PND 21 by anesthetic overdose and quickly perfused wilh ice-cold $2 \%$ paralormaldehyde, and then the brains were removed and postfixed for $2 \mathrm{hr}$ in $2 \%$ paraformaldehyde Following postfix, brains were placed in $70 \% \mathrm{EtOH}(2 \times 1 \mathrm{hr})$ and then left overnight in $70 \% \mathrm{EtOH}$. The next day, brains were dehydrated through a series of baths of increasing percentages of $\mathrm{EtOH}(75 \%, 80 \%$, $90 \%, 95 \%, 100 \%$ ) for $1 \mathrm{hr}$ each. Each brain was then placed in EtOH $p$-dioxaine (50:50) for $2 \mathrm{hr}$ and left overnight in 100\% p-dioxaine. Brains were then embedded in paraffin, and $7-\mu \mathrm{m}$-thick sections were cut on a microtome and mounted on gelatin-coated slides.

Sections were deparaffined and prepared for BrDU immunocytochemistry. The fixed tissue was first treated with $0.1 \%$ trypsin in $0.1 \mathrm{M}$ Tris buffer with $0.1 \% \mathrm{CaCl}_{2}$ at $37^{\circ} \mathrm{C}$ for $20 \mathrm{~min}$. Slides were then rinsed with phosphate-buffered saline PBS (pH 7.4) and denatured with $2 N$ $\mathrm{HCl}(1 \mathrm{hr})$, quick rinsed in $\mathrm{PBS}(\mathrm{pH} 6.0$ ), and incubated in mouse antiBrDU antibody (Becton Dickinson) 1:25 in PBS ( $\mathrm{pH} 7.4$ ) for $1 \mathrm{hr}$. Sections were washed (5 min) in PBS ( $\mathrm{pH} \mathrm{7.4)} \mathrm{and} \mathrm{further} \mathrm{processed}$ using a Vector $\mathrm{ABC}$ Labeling Kit (Vector Labs), and then the labeling was demonstrated with 5\% diaminobenzidine (DAB) in PBS (pH 7.4) plus $0.005 \%$ hydrogen peroxide. Some sections were enhanced by adding cobalt chloride $(1 \%)$ and nickel ammonium sulfate $(1 \%)$ in $0.1 \mathrm{M}$ PBS ( $\mathrm{pH} 7.4$ ) to the DAB solution. Reaction product from the above protocol stained BrDU-positive cell nuclei dark brown (Takahashi et al., 1992) or, when enhanced, black. Both procedures resulted in comparable staining, and the data from both were pooled for analysis.

Sections were viewed under a bright-field microscope and camera lucida drawings were made using a $20 \times$ objective and a drawing tube. Labeled neurons were charted, and the drawings of the PND 21 cortex subsequently were divided into ten equal bins spanning the radial distance from the pia to the underlying white matter. Counts of BrDUlabeled cortical neurons were made in areas $400 \mu \mathrm{m}$ in width, and the height of the bins was the same for each bin within a section but changed across sections depending upon the radial distances from white matter to pia. The total numbers of labeled neurons within each of the 10 bins were expressed as percentages of the total numbers of labeled neurons within all 10 bins counted within a section. Counts were averaged from two separate and nonadjacent sections chosen from the same approximate rostrocaudal level through the somatic sensorimotor cortex. In PND 5 cortices similar counts of BrDU-labeled neurons were made in comparable areas.

In vitro aggregation. Early postmitotic neurons were differentially labeled in the cortices of both reeler $(r l / r l)$ and wild type $(+/+)$ mice. Pregnant reeler $(r l / r l)$ mice $(n=2)$ were given intraperitoneal injections of $\mathrm{BrDU}(140 \mathrm{mg} / \mathrm{kg})$ dissolved in $0.007 \% \mathrm{NaOH}$ on the morning of E12, at the same time their wild-type E12 counterparts $(n=2)$ received $0.1 \mathrm{mC}$ i injections of ${ }^{3} \mathrm{H}$-thymidine (thy) (specific activity, 44 $\mathrm{Ci} / \mathrm{mmol}$ ). Four days later (E16) laparotomies were performed on individual dams. This allowed time for the early postmitotic neurons to migrate into the cortical plate, as well as allowing the remaining ventricular zone precursors to continue to cycle and dilute out the birthdate markers. In a separate set of animals the injection protocol was reversed for the groups: a pregnant reeler dam was injected with ${ }^{3} \mathrm{H}-$ thy on $\mathrm{E} 16$, while an age-matched wild-type $(+/+)$ counterpart was injected with $\mathrm{BrDU}$. In this group, laparotomies were performed $2 \mathrm{~d}$ later on E18, allowing for the dilution of the birthdate markers in cells continuing to divide and ensuring that neurons were cultured prepartum to ensure good survival and growth in vitro. Fetal pups were removed under sterile conditions and decapitated, and their brains removed. Cortices of the embryos were dissected, minced, and placed in D-MEM/F14 media (GIBCO) supplemented with 5\% horse serum (GIBCO), $5 \%$ fetal bovine serum (GIBCO), $25 \mathrm{mg} / \mathrm{ml}$ transferrin, $25 \mathrm{mg} / \mathrm{ml}$ insulin, $25 \mathrm{ng} /$ ml sodium selenite (Sigma). Each dam supplied six to eight pups from which cortical tissue was collected and mechanically dissociated by titrating through a series of pipettes with decreasing diameters. Pups from one reeler $(r l / r l)$ and one wild-type $(+/+)$ mated dam, collected separately, supplied the tissue for use in a single coculture. Cell viability (as judged by trypan blue exclusion) was approximately $87 \%$ in the E12-injected tissue and $75 \%$ in the E16-injected tissue. Cells were plated in growth medium at a density of $1 \times 10^{7}$ cells $/ 60 \mathrm{~mm}$ dish (Falcon), with each of reeler and wild-type cells supplying half $\left(0.5 \times 10^{7}\right.$ cells/ dish) of the population in a tissue culture dish. Dishes were incubated at $37^{\circ} \mathrm{C}$ with $5 \% \mathrm{CO}_{2}$ on a rotary shaker at $70 \mathrm{rpm}$ for $5 \mathrm{~d}$. Each dish 

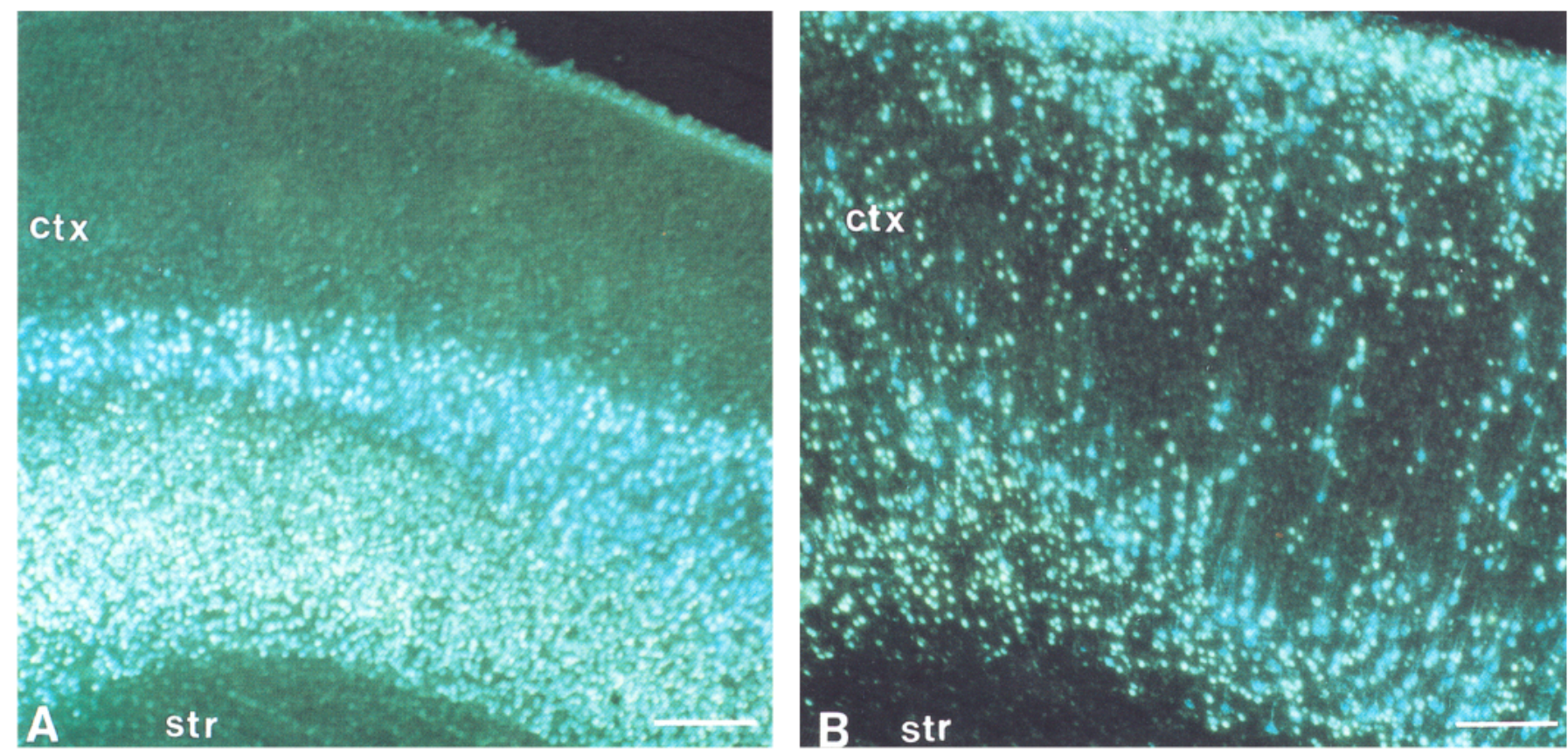

Figure 1. Photomicrographs of PND 5 cortical neurons in control heterozygous $(+/ r l)(A)$ and homozygous $(r l / r l)(B)$ reeler littermates retrogradely labeled by injections of true blue (blue label) into the cerebral peduncles and diamidino yellow (yellow/green label) into the thalamus on PND 2. Labeled neurons in control heterozygous $(+/ r l)$ cortex $(A)$ are confined to bands (true blue, layer V; diamidino yellow, layer VI) within the deep half of the cortex. However, labeled neurons in the reeler $(r l / r l)(B)$ are dispersed radially across the cortex with tight clustering of some labeled neurons at the most superficial margin of the cortex. str, striatum; ctx, cortex. Scale bar, $60 \mu \mathrm{m}$.

was inspected immediately after plating to ensure that neurons were completely dissociated. Cultures were supplemented with fresh growth media after $2 \mathrm{~d}$ in vitro.

After $5 \mathrm{~d}$ the resulting aggregates were rapidly fixed with ice-cold $70 \% \mathrm{EtOH}$ and stored overnight in the refrigerator $\left(4^{\circ} \mathrm{C}\right)$ in $70 \% \mathrm{EtOH}$. Aggregates were collected the following day and dehydrated through a series of alcohol baths. They were then processed with $p$-dioxane (as described above) and embedded in paraffin. Microtome sections of 5$7 \mu \mathrm{m}$ were mounted on gelatin or $2 \% 3$-aminopropyltriethoxysilane (Sigma)-coated slides and processed for BrDU as described above. Slides then were coated with Kodak NTB-2 nuclear track emulsion in a darkroom and exposed between 5 and 9 weeks at $4^{\circ} \mathrm{C}$. The emulsion was developed in Kodak D-19 at $15^{\circ} \mathrm{C}$, rinsed, and fixed with $25 \%$ sodium thiosulfate.

Camera lucida drawings were made of cross sections through the middle of randomly selected, individual, medium-sized aggregates. Aggregates from the two E12 injection cocultures ( $n=50$ aggregates) were analyzed according to the three different cell types observed: (1) $\mathrm{BrDU}$ (reeler) E12-labeled neurons, (2) ${ }^{3} \mathrm{H}$-thy (wild-type) E12-labeled neurons, and (3) unlabeled (reeler and wild-type) cells. Since E12 is very early in cortical development the vast majority of unlabeled cells (both reeler and wild-type) must have become postmitotic at later times. Thus, unlabeled cells were the progeny of precursors that continued to undergo mitosis after injection of either BrDU or ${ }^{3} \mathrm{H}$-thy and therefore diluted out the birthdate markers, or never took up the markers in the first place. In the E16 injection coculture experiment ( $n=25$ aggregates), the three cell types included for analysis were (1) BrDU-labeled (wild-type) E16-labeled neurons, (2) ${ }^{3} \mathrm{H}$-thy-labeled (reeler) E16-labeled neurons, and (3) unlabeled (wild-type and reeler) neurons. Since the animals were not sacrificed until E18 (allowing $2 \mathrm{~d}$ for the dividing cells to dilute out the birthdate markers), unlabeled cells in the E16 injection aggregates would likely be a mixture of earlier $(<\mathrm{E} 16)$ postmitotic neurons that were postmitotic before the birthdate marker injections, and later ( $>$ E16) postmitotic neurons and glia that diluted out, or never took up, the markers. Sections were counterstained with safranin $(1 \%)$. The distances between the celi membranes of individual BrDU- and ${ }^{3} \mathrm{H}$-thy-labeled cell perikarya were obtained and the spatial distributions of labeled cells within the aggregates were analyzed.

\section{Results}

Retrogradely labeled cortical projection neurons are situated in both superficial and deep reeler cortex

Neurons retrogradely labeled from cerebral peduncle injections with true blue and from thalamic injections with diamidino yellow in heterozygous control $(\mathrm{rl} /+)$ mice were invariably confined within the deep half of the cortex to narrow bands corresponding to layer $\mathrm{V}$ and layer VI, respectively (Fig. 1A). True blue retrogradely labeled corticofugal neurons (Figs. 1A, 2A,C) were always in a distinct layer $\mathrm{V}$ band regardless of age at time of injection or sacrifice. However, in the reeler $(\mathrm{rl} / \mathrm{rl})$ cortex presumptive layer $\mathrm{V}$ and layer VI neurons were initially broadly distributed (Fig. 1B), both superficially and deeply in the cortex. Many of the true blue and diamidino yellow retrogradely labeled neurons were tightly clustered at the superficial aspect of the reeler cortex. Interestingly and unlike in wild-type cortex, with further development the distribution of true blue-labeled (presumptive layer V) neurons in the reeler changed. Early injection (PND 2) and sacrifice (PND 5) true blue-labeled neurons appeared to be prevalent in both the deep and superficial portions of the cortex (Fig. 1B). Later injection (PND 19) and sacrifice (PND 21) revealed an inverted distribution (true blue-labeled neurons were situated superficially) (Fig. 2D) compared to that seen in heterozygous control $(r l /+)$ cortex, which accords with conventional descriptions that the reeler mutation results in a linear inversion (superficial-to-deep) among cortical phenotypes (Goffinet, 1979; Caviness, 1982; Takahashi et al., 1992). These results on the changing distributions of retrogradely labeled corticofugal neurons during reeler development are similar to the observations of Inoue et al. (1991) that the distributions of HRP retrogradely labeled corticospinal neurons in reeler change between PND 10 and PND 60. 

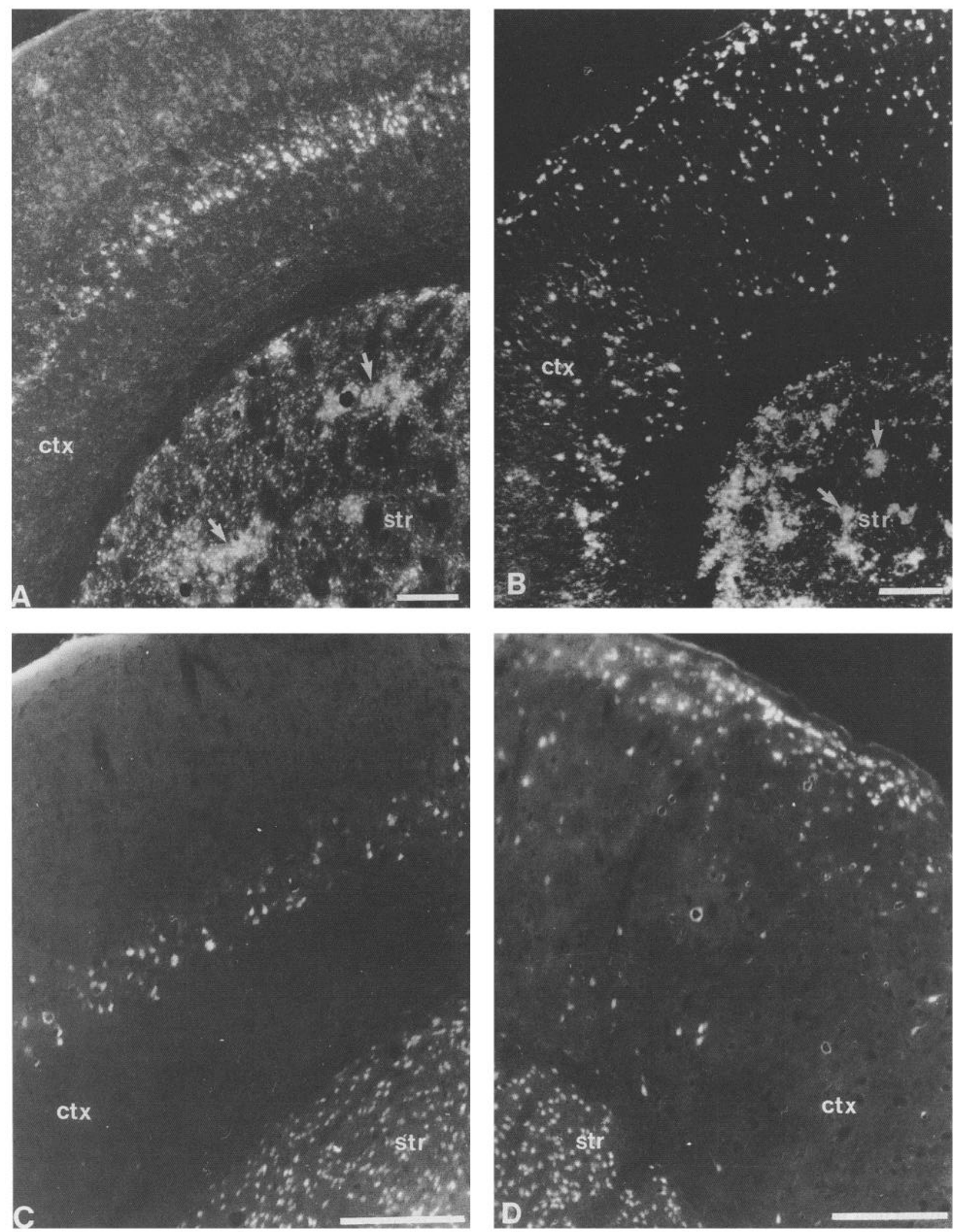

Figure 2. Fluorescence photomicrographs of true blue-labeled neurons in control heterozygous $(+/ r l)(A$ and $C)$ and homozygous $(r l / r l)(B$ and $D)$ reeler littermates retrogradely labeled by injections into the cerebral peduncles. Labeled neurons in heterozygous $(+\mid r l)$ mice injected on PND 2 and sacrificed on PND $21(A)$, and injected on PND 19 and sacrificed on PND $21(C)$, are confined to bands (layer V) within the deep half of the cortex. True blue-labeled cortical neurons in homozygous reeler $(r l / r l)$ mice injected on PND 19 and sacrificed on PND $21(D)$ were most frequent in the superficial cortex and diminished in numbers toward the deep cortex. $B$ shows a more diffuse distribution of true blue-labeled cortical neurons in a homozygous $(r l / r l)$ reeler injected on PND 2 and sacrificed on PND 21 that is similar to the distribution of labeled neurons observed in $(r l / r l)$ reeler PND 2 injection/PND 5 sacrifice mice (see Fig. 1B). Arrows in $A$ and $B$ point to striatal patches that are labeled by early but not late (note diffuse striatal labeling in $C$ and $D$ ) midbrain injections of true blue. str, striatum; $c t x$, cortex. Scale bars, $200 \mu \mathrm{m}$. 
Unlike the single band of true blue-labeled reeler neurons in the heterozygous control $(r l /+)$ mice, counts of true blue-labeled neurons in reeler $(r l / r l)$ cortices revealed that the labeled reeler neurons were distributed bimodally on PND 5. Although in reeler $(\mathrm{rl} / \mathrm{rl})$ animals true blue-labeled (presumptive layer $\mathrm{V}$ ) neurons appeared across the entire radial cortical axis (Fig. 1B), there was a significant effect of the distribution of true bluelabeled neurons across the 10 bins spanning the radial cortical axis $\left(F_{9,80}=11.3, p<0.05\right)$. True blue retrogradely labeled neurons were most prevalent in two distinct bands (Fig. $3 B$ ). Neuman-Keuls tests revealed that the superficialmost bins 1 and 2 individually contained significantly $(p<0.05)$ more true bluelabeled neurons than any individual intermediate bins $3-8$. The deepest bins 9 and 10 also each contained significantly $(p<$ $0.05)$ more true blue-labeled neurons than individual intermediate bins $3-8$, but the counts in the two deepest bins were not different $(p>0.05$ ) from those in bins 1 and 2 (Fig. $3 B$ ).

The distribution of retrogradely labeled neurons along the radial axis of the homozygous $(r l / r l)$ at PND 5 was different from that seen after true blue injections on PND 19 and sacrificed on PND 21. True blue-labeled (presumptive layer V) neurons were located primarily in the dorsal half of the reeler cortex (bins 15) after PND 19 injections, and their numbers diminished steadily with closer approach to the white matter (Fig. 2D). More than half of the true blue-labeled (presumptive layer $\mathrm{V}$ ) neurons were located in superficial bins $1-3$ (Fig. $3 B$ ). The bottom-most three bins in the PND 19 true blue injection/PND 21 sacrifice reeler cortices contained only a very small proportion of all the true blue-labeled cells. An ANOVA revcalcd a significant interaction $\left(F_{9,150}=37.7, p<0.05\right)$ between the distributions of neurons along the radial axis and the early reeler (PND 2 true blue injection/PND 5 sacrifice) versus late reeler (PND 19 true blue injection/PND 21 sacrifice) cortices. These results suggest that layer $\mathrm{V}$ neurons are initially prominent in both deep and superficial PND 2 reeler cortex, but by PND 21 relatively few neurons in the deep reeler cortex maintain projections as far as the cerebral peduncles.

Results from a single reeler animal injected with true blue on PND 2 and sacrificed on PND 21 revealed a pattern of labeling corresponding to that seen in cortices on PND 5 (Fig. 3B). Reeler neurons retrogradely labeled by early true blue injections are still present on PND 21 in a distribution more representative of their early widespread, than of their late inverted distribution (Fig. 1B). A second reeler mouse injected with true blue on PND 2 and sacrificed on PND 21 had weak labeling that, while not sufficient to quantify, showed the same distribution of retrogradely labeled neurons across both superficial and deep cortex. The distributions of true blue-labeled neurons in the cortices of PND 2 injection/PND 21 sacrifice control heterozygous $(+/ r l)$ pups $(n=4)$ were indistinguishable from those of PND 19 true blue injection/PND 21 sacrifice and PND 21 heterozygous control $(r l+)$ animals (compare Fig. $2 A$ with Figs. 1A, 2C).

Injections of true blue into the cerebral peduncles often resulted in retrograde labeling of striatal neurons, presumably by uptake through their projections to the substantia nigra that the cerebral peduncle true blue injections sometimes infringed upon. The mammalian striatum is compartmentalized into patch and matrix compartments based upon neurochemicals, neurotransmitter receptors, and neuroanatomical projection profiles (Johnston et al., 1990). During development patch neurons are born and send their projections to the substantia nigra before matrix neurons. Therefore, striatal patches can be preferentially labeled
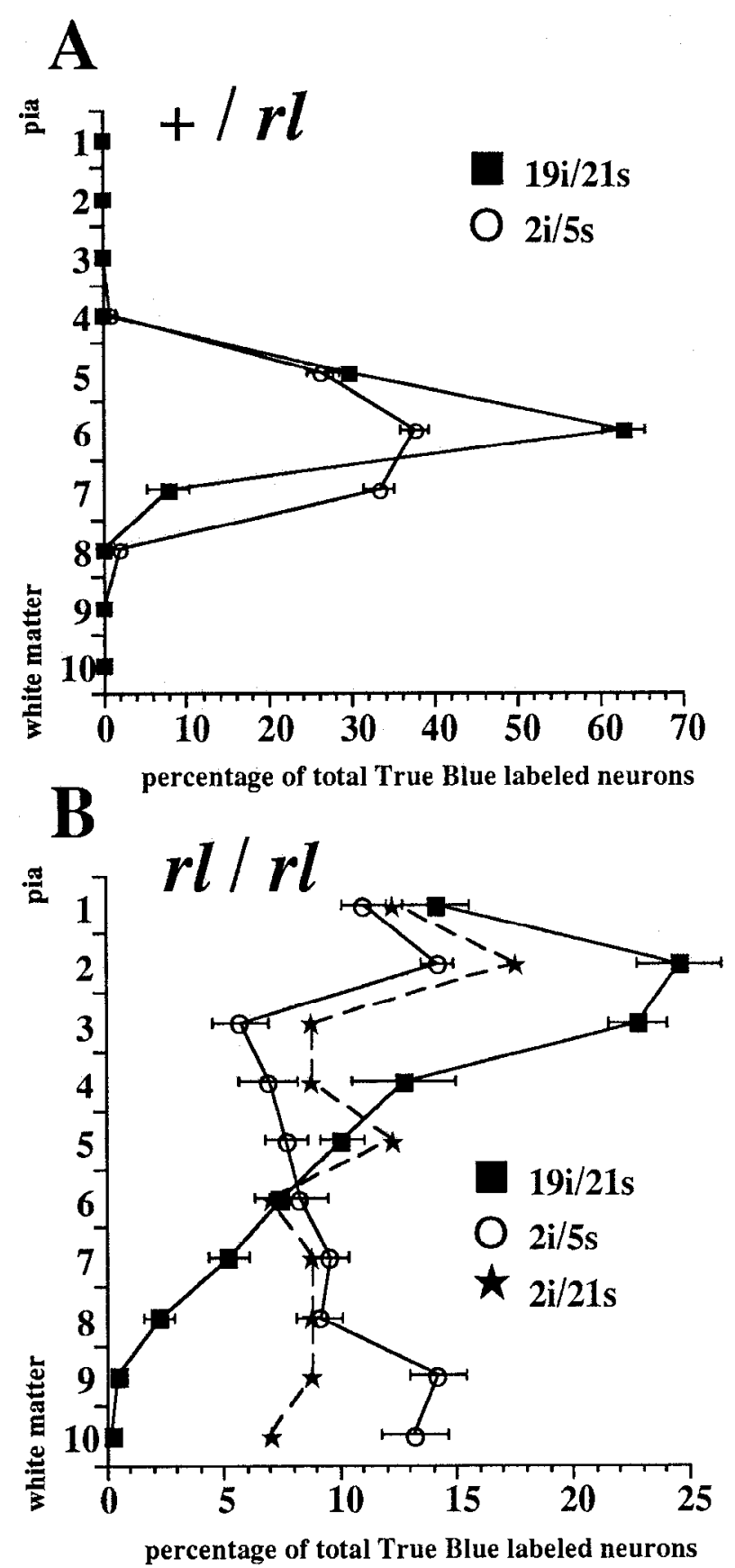

Figure 3. Distributions of true blue-labeled cortical cells in control heterozygous reeler $(+/ r l)(A)$ and homozygous reeler $(r l / r l)$ mice $(B)$ injected (PND 2) and sacrificed (PND 5) early $(n=8+/ r l$ and $9 r l$ $r l)$, injected late (PND 19) and sacrificed late (PND 21) $(n=8+/ r l$ and $8 r l / r l$ ), and injected early (PND 2) and sacrificed late (PND 21) $(n=4+/ r l$ and $1 r l / r l)$. Measurements are expressed as the percentages $( \pm$ SEM) of the total labeled population in each of 10 bins represented on the ordinate as extending from the pial surface (bin $I$ ) to white matter (bin 10).

using an early postnatal (<PND 7) injection of a retrograde tracer into the substantia nigra (Fishell and van der Kooy, 1987). In some of both $(r l / r l)$ and $(r l /+)$ mice, early injections (PND 2) produced patchy striatal staining that resulted from the labeling of the early projections of striatal patch neurons. The presence of a patchy distribution of early striatonigral-projecting neurons in some $(r l / r l)$ animals seems to indicate that the reeler 


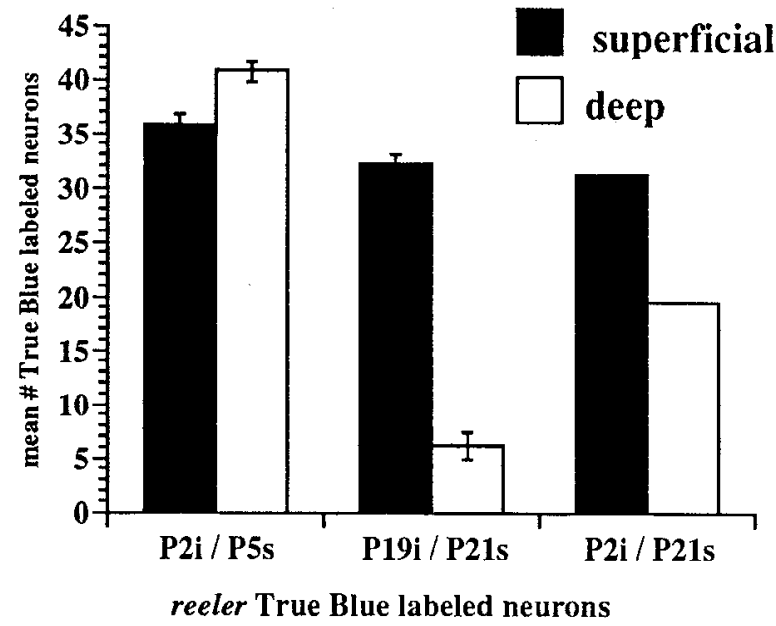

Figure 4. Counts of true blue-labeled neurons in the superficial and deep halves of $400-\mu \mathrm{m}$-width areas of the cortex of homozygous ( $r l$ l $r l)$ reeler mice injected on PND 2 and sacrificed on PND $5(n=9)$, injected on PND 19 and sacrificed on PND $21(n=8)$, and injected on PND 2 and sacrificed on PND $21(n=1)$. Counts were corrected for section thickness using the Abercrombie (1946) correction factor. Data represent means ( \pm SEM).

mutation does not affect striatal compartmentation. Despite the similar adhesive mechanisms operating in deep cortical neurons and striatal patch neurons (Krushel and van der Kooy, 1993), these results in reeler suggest that additional (perhaps redundant) mechanisms help to compartmentalize the striatum.

Sample counts of true blue-labeled neurons revealed a significant $\left(F_{1,28}=100.5, p<0.05\right)$ loss of approximately $40 \%$ of the labeled cells in both heterozygous control $(r l /+)$ and reeler $(r l / r l)$ cortices in the PND 19 injection/PND 21 sacrifice mice compared to the number of labeled cells in the PND 2 injection/ PND 5 sacrifice mice. In the control heterozygous $(\mathrm{rl} / \mathrm{+})$ cortex this loss in labeling presumably results from cell death and/or axon retraction occurring within the band of layer $V$ neurons in the deep cortex. In reeler $(r l / r l)$ mice there was a comparable loss in numbers to that in the control heterozygous $(\mathrm{rl} / \mathrm{+})$ mice except that the loss could be accounted for primarily by the loss of labeled neurons in the deep half of the cortex (Fig. 4). True blue-labeled corticofugal reeler neurons were prevalent throughout the superficial and decp halves of the cortex at PND 5 , but PND 19 injections were no longer able to label neurons in the deep cortical half. However, preliminary results from a single animal reveal that some corticofugal neurons labeled early (PND 2) were still present on PND 21 (Fig. 2B). Based on the numbers of retrogradely labeled corticofugal neurons in this reeler $(r l / r l)$ mouse, we suggest that perhaps $40 \%$ of the loss of deep reeler neurons is due to axon retraction and $60 \%$ of the loss is attributable to cell death. Indeed, these deep projection neurons that regress in reeler can be said to be in an ectopic position based on thalamic inputs (Caviness and Frost, 1983; Molnar and Blakemore, 1992) in the inverted architecture of the reeler $(r l / r l)$ cortex.

The earliest-born reeler cortical neurons are located superficially

The difference in the distributions of early-born BrDU-labeled neurons between reeler ( $r l / r l)$ and control heterozygous $(r l /+)$ cortices at PND 21 mimicked the dispersed pattern observed in the early (PND 5 sacrifice) true blue labeling. Independent of the early ages at time of BrDU injection (E11, E12, or E13), labeled neurons in control heterozygous $(r l /+)$ cortices were restricted to the deep cortex (Figs. 5A, 6A-C). Later-labeled (E13) cells occupied more of the superficial bins within the $(r l /+)$ deep cortex than did the earlier-labeled cells. The numbers of BrDUlabeled neurons were relatively consistent across all three labeling times (E11, E12, and E13), and the numbers labeled at one of these ages were never more than three times greater than at any of the other ages. The results indicate that our injections aimed to label deep-fated neurons in the control heterozygous $(r l+)$ mice were different enough across injection age groups to mark positional variabilities within deep cortex associated with birthdate date. No attempt was made to analyze the distributions according to control heterozygous $(\mathrm{rl} / \mathrm{+})$ cortical layers (II-VI), and instead a radial division of the cortex into equalsized bins allowed direct spatial comparisons between homozygous reeler $(r l / r l)$ and control heterozygous $(r l /+)$ cortices. In accordance with the known wild-type deep-superficial neurogenic gradient (Angevine and Sidman, 1961; Smart and Smart, 1982; van der Kooy and Fishell, 1987; Miller and Nowakowski, 1988), E11-labeled neurons in the control heterozygous $(\mathrm{rl} / \mathrm{+})$ cortices were located entirely within bins $5-10$, with more than $40 \%$ in bin 10 alone. Heterozygous control $(r l+)$ E12- and E13labeled neurons were also present primarily in deep bins, with E13-labeled neurons the most superficially represented population within the deep bins.

In homozygous $(r l / r l)$ cortex E11- and E12-labeled neurons made up significantly larger proportions of the superficialmost cortical populations than did the E13-labeled neurons. In homozygous $(r l / r l)$ pups, regardless of age at the time of BrDU injections, some labeled early postmitotic (presumptive deeplayer) neurons were prevalent across the entire radial expanse of the cortex (Figs. 5B, 6A-C), reminiscent of early (PND 2 injection/PND 5 sacrifice) true blue labeling. Both of the two earliest BrDU injections (E11 and E12) resulted in distributions of labeled cells primarily in two prominent bands in the reeler cortex (Figs. $5 B, 6 A, B$ ). One band was located superficially toward the pia, and one band deep near the white matter, with more of the E11- and E12-labeled reeler neurons in the superficial band. The area between these two bands (the intermediate bins) had a relatively smaller number of labeled neurons. Reeler neurons labeled as postmitotic on E13 were distributed more like their control heterozygous $(r l /+)$ cohorts (with the majority situated deep in the reeler cortex) than neurons labeled on either E11 or E12, implying that the reeler deficit differentially affects early versus later postmitotic cortical neurons within the early postmitotic population. Thus, only a subpopulation of presumptive deep-layer neurons are affected by the reeler mutation, and the majority of those affected neurons become postmitotic at the earliest times in cortical neurogenesis.

A comparison of genotype with the distribution of labeled neurons across bins at PND 21 and with age at the time of BrDU injection using an ANOVA revealed a significant three-way interaction $\left(F_{18,250}=64.8, p<0.05\right)$. The deepest bin (10) clearly reveals the difference between the distributions of early- and later-labeled early postmitotic neurons in homozygous $(\mathrm{rl} / \mathrm{rl})$ when compared to control heterozygous $(r l /+)$ cortices. Counts of the labeled neurons in bin 10 revealed a significant interaction $\left(F_{2,25}=161.4, p<0.05\right)$ betwecn age at time of BrDU injection and genotype. In control heterozygous $(\mathrm{rl} / \mathrm{+})$ cortex about $40 \%$ of E11-labeled neurons were located in bin 10. These earliest postmitotic cortical plate neurons correspond in both time of 

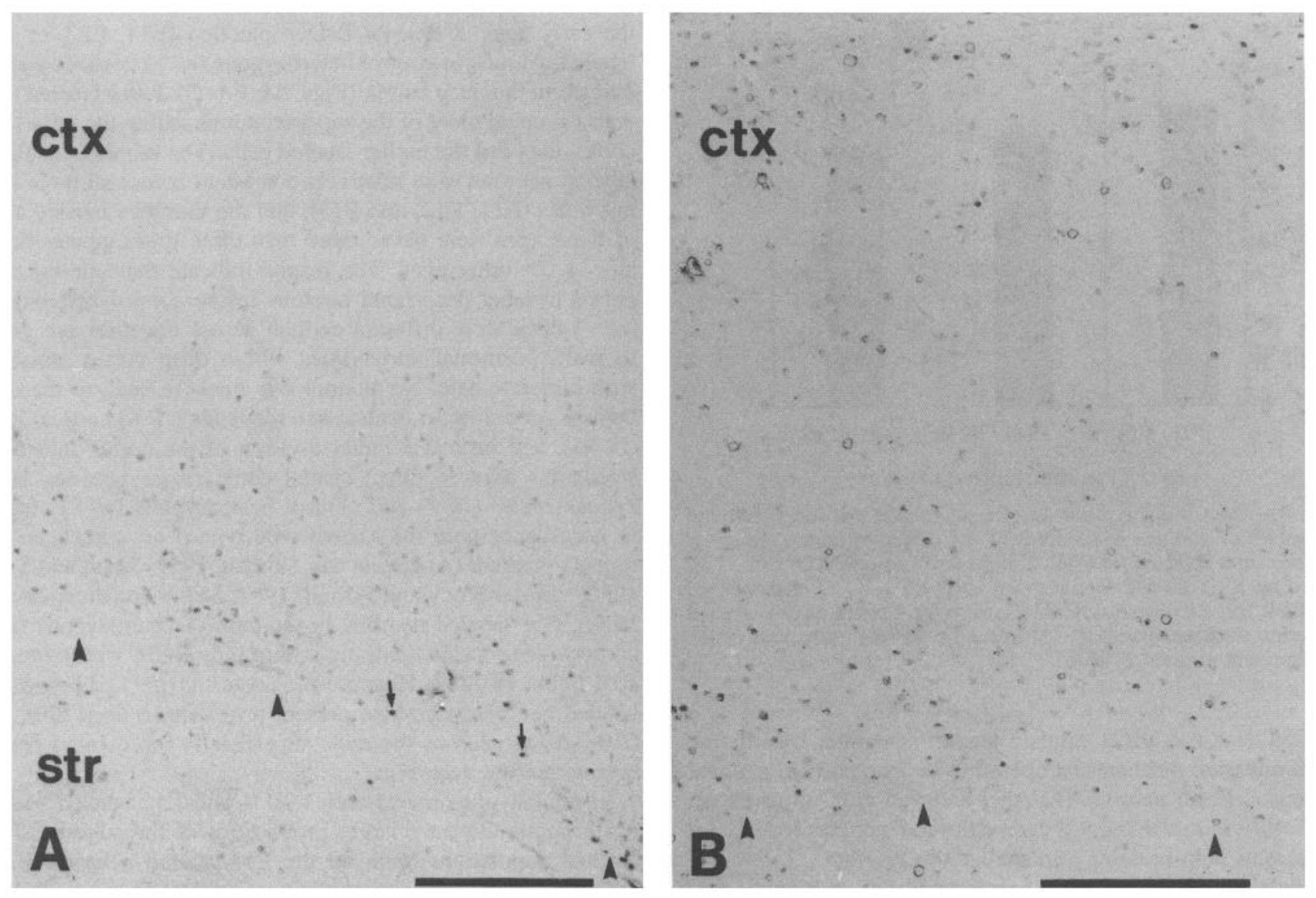

Figure 5. Photomicrographs of E11 BrDU-labeled cortical neurons from control heterozygous $(+/ r l)(A)$ and homozygous reeler $(r l / r l)(B)$ littermates. Labeled neurons in heterozygous $(+\mid r l)$ mice $(A)$ are primarily restricted to the deepest portion of the cortex. A slightly higher magnification of the cortex of a E11 homozygous reeler $(r / / r l)(B)$ reveals the presence of labeled cells in both the superficial and deep cortex. Arrowheads point to top of corpus callosum in both $A$ and $B$. Arrows in $A$ point to BrDU-labeled presumptive subplate cells in the control heterozygous $(r l /+)$ cortex. str, striatum; ctx, cortex. Scale bars, $100 \mu \mathrm{m}$.

origin and position within the mature cortex with deep layer VI and subplate neurons (Raedler and Raedler, 1978; Konig and Marty, 1981; Bayer and Altman, 1990; McConnell et al., 1994). Newman-Keuls tests revealed that a significantly $(p<0.05)$ larger proportion of heterozygous control $(r l /+)$ E11- and E12labeled neurons were at the bottom of the cortex in bin $10 \mathrm{com}$ pared to E11- and E12-labeled neurons in homozygous $(r l / r l)$ cortex, but there was no significant $(p>0.05)$ difference in the proportion of the E13-labeled neurons in bin 10 comparing heterozygous control $(r l /+)$ and homozygous $(r l / r l)$ cortices (Fig. $6 A-C$ ). Together with the long-term (PND 2 injection/PND 21 sacrifice) true blue labeling of presumptive deep-layer projection neurons, these results indicate that during reeler cortical development a significant number of neurons that become postmitotic on E11, E12, and E13 survive in the deep cortex until at least PND 21.

A comparison in reeler cortex of E11-, E12-, and E13-labeled populations in the superficialmost bin 1 revealed a significant $\left(F_{2,25}=47.8, p<0.05\right)$ effect of birthdate. The percentages of E11-labeled (36\%) and E12-labeled (25\%) neurons in bin 1 were significantly $(p<0.05)$ larger than the percentage of the E13labeled $(10 \%)$ neurons in bin 1 . There were no significant differences $(p>0.05)$ in reeler with respect to the populations of E11, E12, or E13 BrDU-labeled cells within intermediate bins 3-6 (Fig. 6A-C). Given that the majority of E11- and E12-la- beled neurons correspond in fate to deep layer VI and subplate neurons (as judged by their corresponding position in control heterozygous $(r l /+)$ littermates), then we suggest that these earliest of the cortical plate and subplate neurons are preferentially affected by the reeler mutation. Later (E13) postmitotic reeler neurons (with a preferential wild-type fate to reside in more of the superficial positions within the deep cortex; Fig. $3 C$ ) were preferentially located in deep cortical positions [relatively nor$\mathrm{mal}$ in relation to control heterozygous $(\mathrm{rl} /+)$ littermates]. However, some E13-labeled reeler neurons were still positioned more superficially, scattered in the cortex subjacent to the earliest postmitotic neurons. It is important to note that birthdate is a good but not an absolute predictor of which neurons will end up superficially in the homozygous $(r l / r l)$ cortex (a few E11 and E12 neurons end up deep in the reeler cortex), just as birthdate is not an absolute predictor of laminar position in the control heterozygous $(\mathrm{rl} /+)$ cortex. Perhaps the reeler mutation works through a process that correlates with, but is not the same as, becoming postmitotic.

Sample counts of BrDU-labeled cortical neurons in control heterozygous $(r l /+)$ and reeler mice sacrificed on PND 5 and PND 21 indicate a significant $\left(F_{1,53}=14.2, p<0.05\right)$ loss of labeled cells. Both control heterozygous $(r l /+)(n=24)$ and homozygous $(r l / r l)(n=33)$ mice showed an equivalent decline 



percentage of total BrDU labeled cortical neurons

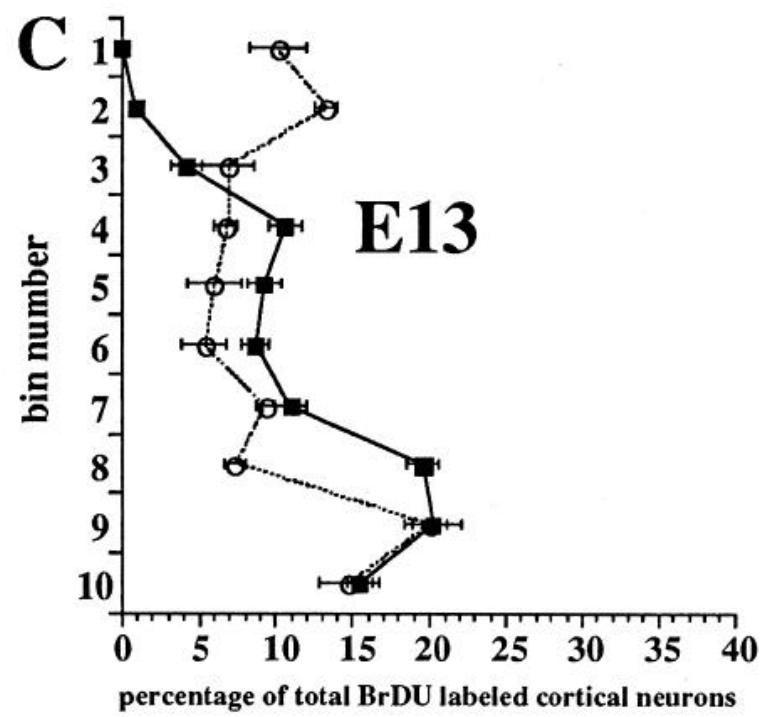

Figure 6. Distributions of BrDU-labeled cells in control heterozygous $(r l+)$ and homozygous $(r l / r l)$ reeler PND 21 dorsolateral cortex expressed as percentages $( \pm$ SEM) of the total labeled populations across 10 bins represented on the ordinate as extending from the pial surface (bin 1) to the white matter (bin 10). Data represent means ( \pm SEM) of BrDU-labeled cells in, for $A$, E11 $(+/ r l)(n=4)$ and $(r l / r l)(n=6)$

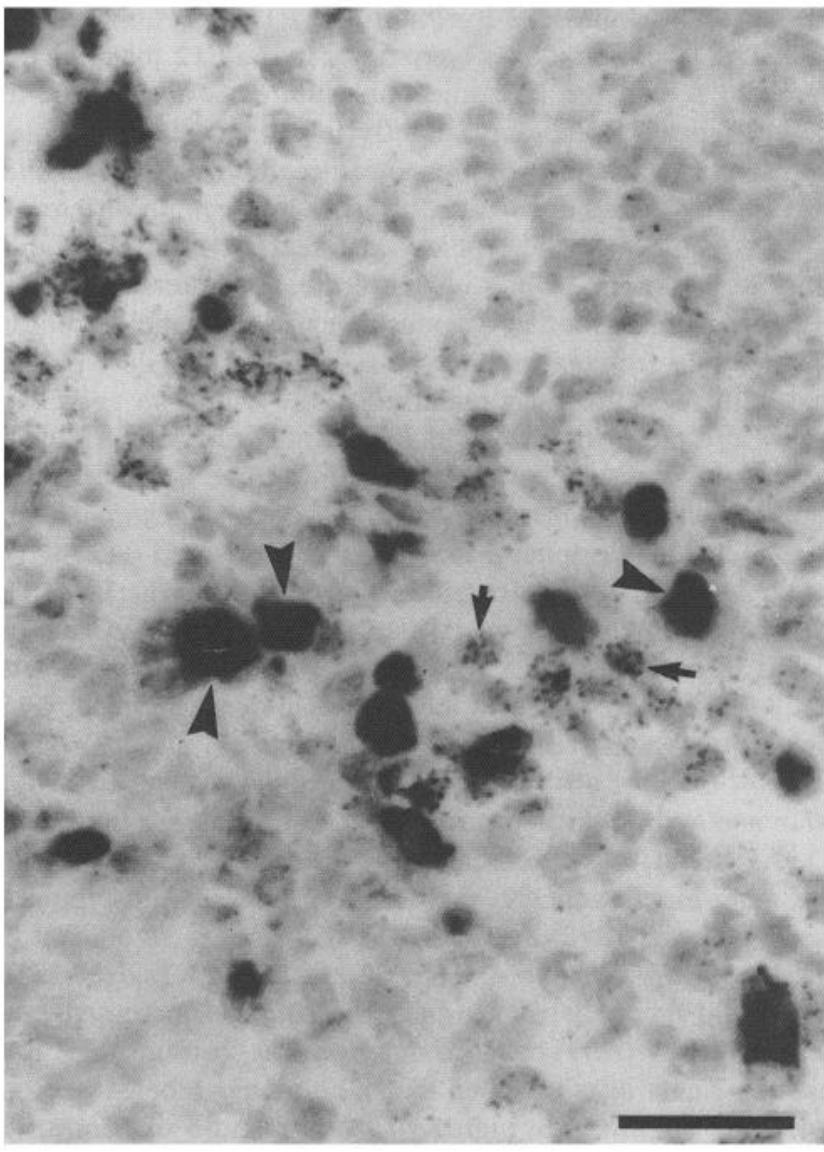

Figure 7. High-power photomicrograph through the center of a cortical aggregate containing wild-type and reeler neurons labeled on E12 with ${ }^{3} \mathrm{H}$-thymidine and BrDU, respectively, and cocultured on E16 for $5 \mathrm{~d}$. The focus is on silver grains, and thus the BrDU and unlabeled cells appear out of focus. Arrows point to ${ }^{3} \mathrm{H}$-thymidine-labeled neurons. Arrowheads point to BrDU-labeled neurons. Scale bar, $20 \mu \mathrm{m}$.

$(\sim 25 \%)$ in labeled cells, presumably due to cell death that takes place between PND 5 and PND 21.

In vitro aggregation of reeler and wild-type neurons

BrDU-labeled cells were readily distinguished by their dark brown (or black when intensified) nuclear staining, and only cells heavily labeled with silver grains (minimum five times more silver grains than the background number over unlabeled cells) were regarded as ${ }^{3} \mathrm{H}$-thymidine labeled (Fig. 7). Labeled cells in both E12 injection and E16 injection aggregates are likely to consist entirely of neurons and not glia, because in rodents glial cells become postmitotic only later in embryogenesis and postnatally (Das, 1979; van der Kooy and Fishell, 1987). Thus, glial precursors continue to divide and dilute out birthdate markers prior to sacrifice. There did not appear to be any difference in the sizes of the E12 injection or E16 injection aggregates. Aggregate diameter ranged from $250 \mu \mathrm{m}$ to $>1000 \mu \mathrm{m}$. Aggregates of between 400 and $600 \mu \mathrm{m}$ were examined in this study. The aggregates revealed equivalent labeling indexes (labeled cells as a percentage of total cells) for the two different birthdate

$\leftarrow$

labeled cortices; $B, \mathrm{E} 12(+/ r l)(n=4)$ and $(r l / r l)(n=7)$ labeled cortices; and $C$, E13 $(+/ r l)(n=4)$ and $(r l / r l)(n=6)$ labeled cortices. 
markers across both F12 injection and F16 injection cultures. The BrDU labeling indexes were $5.9 \%$ in the E12 injection cultures, and $6 \%$ in the E16 injection cultures, while the ${ }^{3} \mathrm{H}$-thy labeling indexes were only slightly lower at $4.7 \%$ and $5.1 \%$, respectively. These close correspondences between the labeling indexes across conditions suggest that there were no differences between reeler and wild-type cortical neurons in terms of their ability to incorporate either of the birthdate markers.

Cross sections of the aggregates revealed that labeled neuronal populations from each genotype (i.e., reeler or wild-type) differed with regard to their radial positions within an aggregate. To measure the distributions of labeled neurons, camera lucida drawings of aggregates were divided into three nonoverlapping concentric circles. Measured radially from the center of each aggregate to the periphery, the center ring covered $0-30 \%$, the middle $31-70 \%$, and the outside $71-100 \%$ of the distance. The ratio of reeler and wild-type labeled neurons to the total number of cells in each aggregate was plotted for all of the aggregates (Fig. 8A,B). An ANOVA on the positional densities of the E12labeled populations revealed a significant main effect $\left(F_{2.294}=\right.$ $41.0, p<0.05$ ) of position demonstrating the preference of both reeler and wild-lype neurons for nore central positions (Fig. $8 A$ ). As might be expected if the E12-labeled reeler neurons were more highly adhesive than the E12-labeled wild-type neurons (Steinberg, 1970; Seeds, 1983), there was a significant interaction $\left(F_{2.294}=10.8, p<0.05\right)$ of position with reeler labeled versus wild-type labeled neurons, showing the increased preference of reeler ( $r l / r l)$ cells for more central positions (Fig. 8A). Newman-Keuls tests revealed that E12-reeler labeled neurons made up a significantly higher $(p<0.05)$ ratio of neurons in the centers of the aggregates than E12-labeled wild-type cells. Consistent with the present findings, De Long and Sidman (1970) found more neurons in the centers of reeler cortical aggregates than in the centers of wild-type cortical aggregates.

Comparing the positional densities of labeled cells within the E16 injection aggregates using an ANOVA revealed no significant interaction $\left(F_{2,144}=1.0, p>0.05\right)$ between position and genotype (Fig. $8 B$ ). Nevertheless, there was a significant main effect $\left(F_{2,144}=21.5, p<0.05\right)$ of position, demonstrating that the proportions of both reeler and wild-type labeled cell populations in the E16 injection aggregates were lower in the centers than in the middle and outside areas of the aggregates. Less than $20 \%$ of all labeled cells were within the central area across the E16 injection aggregates (compared to $50 \%$ across E12 injection aggregates), suggesting that E16 neurons of either genotype are less adhesive than E12 neurons of either genotype (Fig. $8 B$ ).

The average diameter of a cell within an E12 aggregate was about $7 \mu \mathrm{m}$. Nearly $55 \%$ of E12-labeled reeler neurons were within $7 \mu \mathrm{m}$ (one cell diameter) of another labeled reeler neuron, and this percentage declined as the distance (bins) between like-labeled cells increased (Fig. 9A). Only about $13 \%$ of all the E12-labeled reeler neurons were more than $28 \mu \mathrm{m}$ from another labeled reeler neuron. E12-labeled wild-type neurons were not quite as closely associated with other labeled neurons (wt-wt, wt- $r l, r l$-wt), making up smaller percentages (35-40\%) of the nearest-neighbor-measure bin $(7 \mu \mathrm{m})$. This suggests that wildtype E12 neurons are less able to form homotypic associations than reeler E12 neurons. Compared to the distances between labeled neurons in the E12injection aggregates, in E16 injection aggregates neither reeler nor wild-type labeled neurons were associated with other labeled neurons (Fig. 9B). Less than 8\% of reeler E16 injection-labeled neurons were within $7 \mu \mathrm{m}$ of
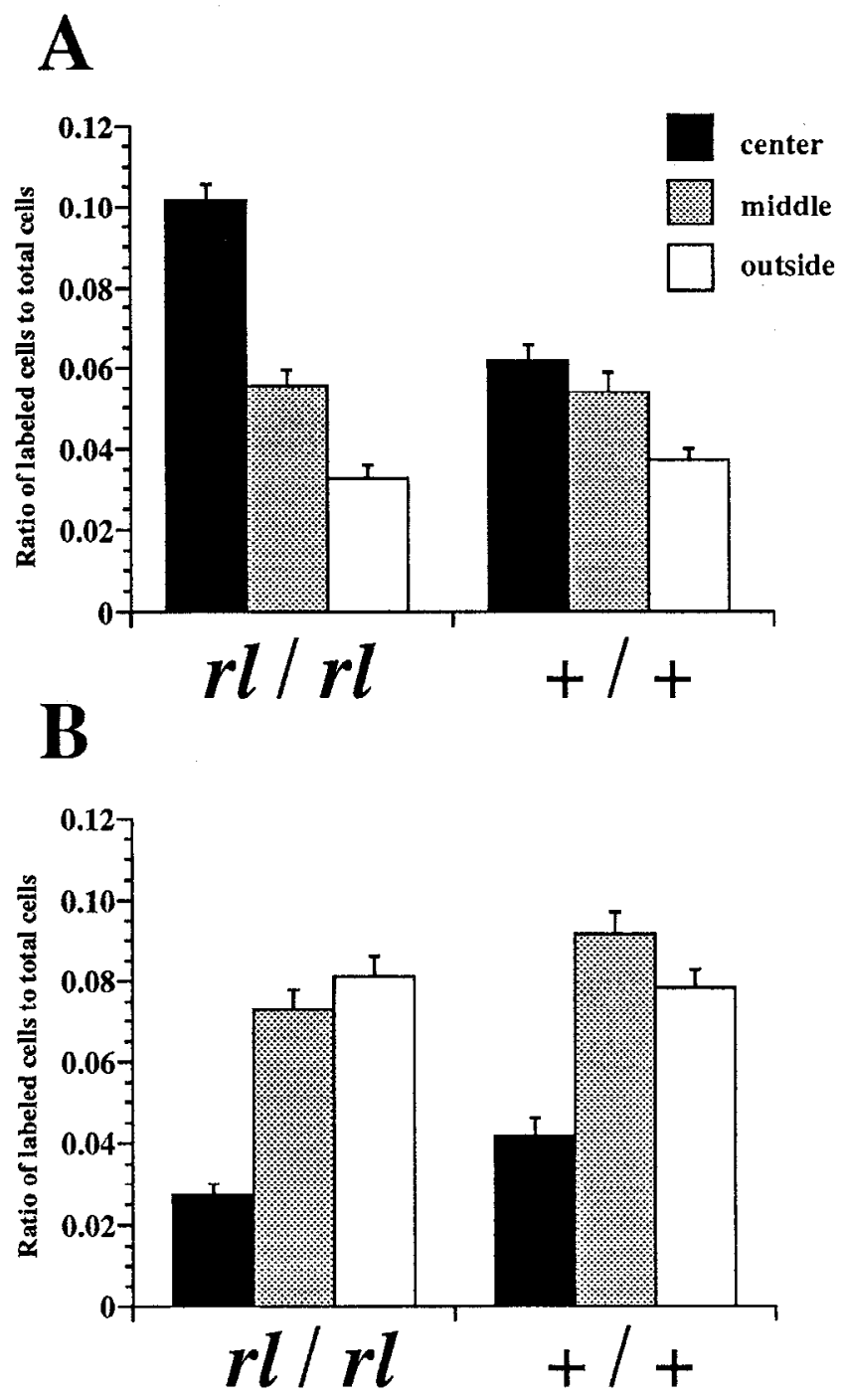

Figure 8. Ratio of the numbers of reeler $(r l / r l)$ and wild-type $(+/+)$ labeled neurons to the total numbers of cells within three concentric circular areas encompassing $0-30 \%, 31-70 \%$, and $71-100 \%$ of the radial distances from the center to the periphery of the aggregates. Cortical neurons from wild-type and reeler mice labeled on E12 and cocultured on E16 $(A)$ are localized toward the center of aggregates. Labeled reeler $(r l / r l)$ neurons were more prevalent in the centers than labeled wild-type $(+/+)$ neurons. Cortical neurons from wild-type and reeler mice labeled on E16 and cocultured on E18 $(B)$ are located more toward the peripheries of the aggregates. Data represent means ( \pm SEM) from 2281 labeled neurons for the E12 reeler + E12 wild-type cultures, and 1114 labeled neurons in the E16 reeler + E16 wild-type culture.

another reeler E16 injection-labeled neuron (compared to 55\% in E12 injection aggregates), and only $13 \%$ of wild-type labeled neurons were within $7 \mu \mathrm{m}$ of other E16 injection-labeled neurons (compared to $35-40 \%$ in El2 injection aggregates). More than of $60 \%$ of the E16 injection-labeled neurons were more than $21 \mu \mathrm{m}$ from other labcled ncurons (compared to $<40 \%$ in the highest E12 injection case) (Figs. 9A,B).

A nearest-neighbor analysis (Clark and Evans, 1954) was used to statistically describe the relative distances between labeled neurons of the same and different genotypes. The shortest distance to another labeled neuron was scored for each labeled neuron in an aggregate. Measures were made of homotypic ( $\mathrm{rl}$ $r l$ and $w(-w)$ and heterotypic ( $r l$-wt and wt- $r l$ ) distances. Within the E12rl $+\mathrm{E} 12 \mathrm{wt}$ aggregates, reeler neurons were found to be 
A



distance from each labeled cell to nearest labeled neighbor $(\mu)$

B

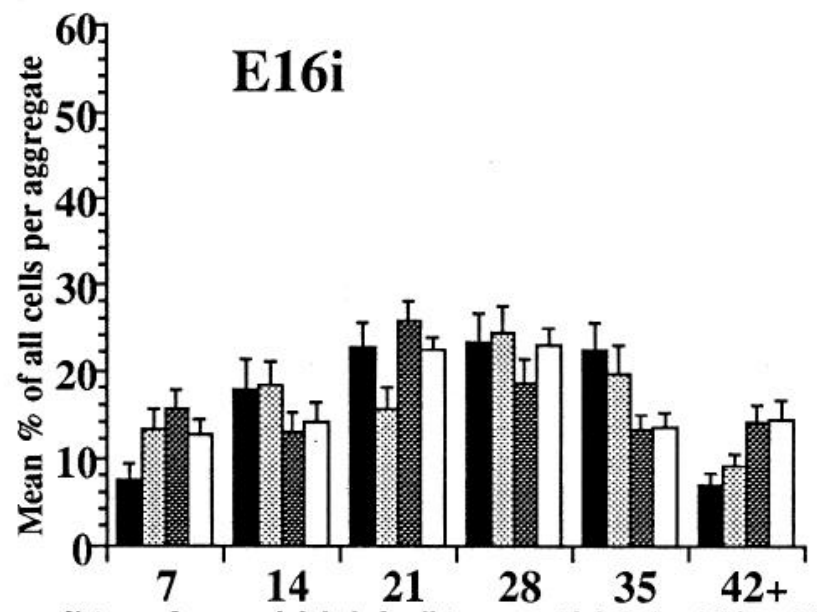

distance from each labeled cell to nearest labeled neighbor $(\mu)$

Figure 9. A, Distances between each E12-labeled wild-type $(+/+)$ neuron and its nearest labeled wild-type and reeler neighbors and between each E12-labeled reeler $(\mathrm{rl} / \mathrm{rl})$ neuron and its nearest labeled reeler and wild-type neighbors were measured in 50 E12 wild-type + E12 reeler aggregates. Measurement distances were grouped into equidistant bins and expressed as percentages $( \pm$ SEM) of each of the different pairs of nearest-neighbor measurements. A total of 1201 wildtype and 1080 reeler neurons were analyzed. $B$, Distances between each E16-labeled wild-type neuron and its nearest E16-labeled wild-type and reeler neighbor and between each labeled reeler neuron and its nearest labeled reeler and wild-type neighbor were measured in 25 E16 wildtype + E16 reeler aggregates. A total of 605 wild-type and 509 reeler neurons were analyzed.

clumped together more often than wild-type neurons. The nearest-neighbor measurements revealed that reeler E12-labeled neurons showed significant $(p<0.05)$ homotypic $(r l-r l)$ clumping in $74 \%$ of the aggregates. In contrast, significant homotypic (wt-wt) clumping of E12-labeled wild-type neurons occurred in only $37 \%$ of the aggregates. Significant heterotypic clumping $(r l$-wt, wt- $r l)$ in the same aggregates was seen in $30 \%$ and $26 \%$ of their respective cases. In E16 injection aggregates, statistical analysis of nearest-neighbor measurements revealed that significant $(p<0.05)$ clumping of homotypic or heterotypic labeled neurons never occurred in more than $24 \%$ of the aggregates. It



Figure 10. Low-power photomicrograph of a E16 wild-type + E16 reeler cortical aggregate in which the wild-type $(+/+)$ cells were labeled with $\mathrm{BrDU}$ (darkly labeled cells). At this magnification only the BrDU-labeled wild-type $(+/+)$ [but not the ${ }^{3} \mathrm{H}$-thymidine-labeled $(\mathrm{rl} /$ $r l)$ ] cells can be visualized to be distributed relatively evenly across the entire aggregate. Scale bar, $100 \mu \mathrm{m}$.

is interesting to note that while E12-labeled reeler neurons were observed to be clumped ( $r l-r l)$ more than E12-labeled wild-type neurons (wt-wt), the two different genotypic populations ( $r l-r l$ and wt-wt) in the E16 injection aggregates did not differ from each other (Fig. 9B). This suggests that the E16-labeled reeler and wild-type neurons do not differ in their adhesion. The lack of adhesive differences between these two genotypes in the E16 injection aggregates was also evident in the equivalent likelihood of each to show heterotypic clumping (i.e., wt- $r l$ and $r l$ wt).

\section{Discussion}

Although reeler neocortical neurons are misorganized spatially, there appear to be the normal types and numbers that are present in the wild-type six-layered cortex (Goffinet, 1984). Despite the cortical misorganization, functional anatomical circuits arise such as those formed by whisker barrel afferents (Caviness and Frost, 1983). Physiological features of reeler neurons, such as those in the visual cortex, retain properties appropriate to their counterparts in wild-type animals (Drager, 1976, 1981). The positions of cortical neurons along the superficial-deep (radial) axis are apparently inverted with respect to birthdate when compared to wild-type or heterozygous reeler mice (Sidman, 1968; Caviness and Sidman, 1973; Goffinet, 1979). This observation led to the hypothesis that reeler homozygous cortex results from 
the inability of later postmitotic neurons to migrate past earlier postmitotic neurons into more superficial positions. The hypothesis, as yet untested, holds that neurons do not exit the radial glial highway, resulting in a "log-jam" distribution, whereby later-born neurons pile up and occupy deeper and deeper positions (Pinto-Lord et al., 1982; see Goffinet, 1984).

The present evidence is not compatible with the view that the reeler mutation affects the migration of all neurons in the cortex, either directly or through their interaction with radial glial cells. The log-jam hypothesis predicts that the distribution of reeler neurons along the superficial-deep axis should be correlated in an outside-in fashion with early-to-late postmitotic dates. This hypothesis predicts that the distribution in reeler mice of presumptive layer V and VI neurons retrogradely labeled from injections into the cerebral peduncles and thalamus (respectively) should always be highest in the superficial cortex. with few in the deep half of the cortex toward the white matter. The distributions of retrogradely labeled neurons in reeler cortex clearly do not support this prediction. In reeler animals sacrificed on PND 5 the distribution of cerebral peduncle neurons was not linear but rather bimodal with large collections of labeled neurons appearing toward both the deep and superficial margins of the cortex. This suggests that rather than an inversion, the reeler mutation causes a split within the deep-layer population, resulting in a portion of the deep-fated neurons being pushed to the top of the cortex, and a portion remaining deep. Further evidence against a primary deficit in radial glial cells in reeler mice comes from the present aggregation studies where differences in reeler versus wild-type neuronal positioning can be detected in the absence of any radially positioned glial cells in such cortical aggregates (Garber et al., 1980).

We hypothesize that the split of early postmitotic reeler neurons might be due to abnormally high adhesion among a subpopulation of the earliest postmitotic neurons that then become impermissive to the migration of later postmitotic neurons. By primarily affecting the earliest postmitotic deep-layer cortical neurons, reeler results in a phenotypic cortical split into a superficial subpopulation (the earliest-born of the early postmitotic neurons) and a deep subpopulation (the later-born of the early postmitotic neurons). Later postmitotic subpopulations of the early postmitotic neurons (as well as late postmitotic populations) are relatively unaffected by the reeler mutation. Thus, these later postmitotic subpopulations may be able to sort themselves out in a relatively wild-type, deep-superficial pattern, below the hypermorphically adhesive earliest postmitotic neurons that are located together at the superficial boundary of the cortex. Consistent with the proposed adhesive changes in reeler cortex, Shur (1982) noted a decrease in galactosyltransferase activity in reeler cortex; however, this change was measured postnatally and may be a secondary sequela or the early embryonic changes that we suggest are critical for the misorganization of reeler cortical laminae.

The present BrDU birthdating data support the hypothesis that during reeler cortical development the earliest postmitotic (E11 and E12) populations of deep-layer neurons tend to be in ectopic (superficial) positions. Later postmitotic (E13) labeled reeler neurons (still presumptive deep-layer neurons) had less ectopic distributions [compared to control heterozygous $(r l /+)$ littermates], which may indicate that they arc less affected by the reeler mutation. Early postmitotic deep-layer cortical neurons have been shown to possess an adhesive affinity that is absent in superficial cortical neurons (Krushel and van der Kooy, 1993).
In early postmitotic (E12) reeler and wild-type aggregates labeled neurons were more clumped than labeled neurons in E16 aggregates of wild-type and reeler neurons, but the early postmitotic (E12) wild-type neurons appear to lack the hyperadhesive quality of E12 reeler neurons. In E12-labeled, but not E16labeled, aggregates reeler $(r l / r l)$ labeled neurons established more homotypic associations, and were consistently closer to the aggregate centers, than their wild-type cohorts. Late (E16-labeled) postmitotic reeler $(r l / r l)$ neurons do not appear to act any differently than their wild-type counterparts; neither show evidence of selective adhesion. The retrograde tracing of presumptive layer $\mathrm{V}$ and VI projection neurons demonstrated tight clustering of the retrogradely labeled neurons selectively in the superficial reeler cortex, which may reflect the high adhesion peculiar to the earliest-born reeler neurons.

Many neurons may be fated to deep or superficial fates prior to exiting the proliferative cycle in the ventricular zone (Crandall and Herrup, 1990; Fishell et al., 1990; McConnell and Kaznowski, 1991; van der Kooy, 1992; Krushel et al., 1993). In mammalian forebrain development layer I neurons are the first postmitotic neurons of the cortical plate (Bayer and Altman, 1990) and they remain (primarily as Cajal-Retzius cells) in the mature cortex as the most superficial neurons (Konig and Marty, 1981; Luskin and Shatz, 1985). Following the birth of layer I cells the earliest postmitotic cortical neurons are fated to differentiate into subplate and deep-layer cortical plate neurons (McConnell et al., 1994). Indeed, the earliest BrDU-labeled postmitotic neurons in control heterozygous $(r l /+)$ cortices were in the deepest portions of the cortex; however, in the homozygous reeler $(r l / r l)$ the earliest-labeled postmitotic neurons appeared primarily in the superficial cortex. This suggests that subplate and deep-layer cortical plate neurons may share the same adhesive component, and therefore the same positional fate. If hyperadhesion ensures that the relatively small number of layer I neurons maintain the superficialmost position in the developing cortex, then the reeler mutation might convert the fates of subplate and early postmitotic deep-layer cortical plate neurons to a layer I neuronal adhesive fate. The earliest cortical neurons of the reeler preplate are misoriented (Crandall and Caviness, 1991), which may be a result of hypermorphic adhesion among this population making them impermissible to the passage of the later postmitotic cortical plate neurons.

$\mathrm{N}$-cadherin mRNA is selectively expressed in deep-layer neurons, and specifically during the perinatal period when deep and superficial neurons are segregating (Redies and Takeichi, 1993). We suggest that the reeler mutation may affect an intrinsic adhesion program in cortical neurons by hypermorphic regulation of an adhesive factor that is peculiar to deep-layer neurons such as N-cadherin. The adhesion mechanism of the earliest postmitotic neurons might be expressed to a greater degree or earlier than normal. In wild-type development deep-layer adhesion may turn on during or after migration to clump laminae, or before migration of later postmitotic neurons to keep the earliest postmitotic neurons in place while later postmitotic populations migrate past. Reeler may act in the $\mathrm{N}$-cadherin regulatory pathway causing either an over- or early expression, resulting in the ectopic positioning of the earliest postmitotic deep-layer neurons. Nevertheless the reeler mutation (mapped to chromosome 5; Goffinet, 1992) is not a hypermorphic mutation of the N-cadherin gene itself (mapped to chromosome 18; Miyatani et al., 1992). The cerebellum of reeler mutants is characterized by the malpositioning and loss of Purkinje neurons and a substantial 
reduction in the granule cell population (Goffinet, 1984; Heckroth et al., 1989; Goffinet, 1992). The arrested migration of reeler Purkinje cells also could be explained by a hypermorphic homotypic cell adhesion mechanism among Purkinje cells, limiting their migration. Perhaps the arrested migration of Purkinje neurons deprives developing granule cells of necessary interactions, without which the granule cells die.

In the cortex the developmental split caused by the hyperadhesion of the earliest postmitotic neurons may be obscured by major regressive changes occurring later postnatally (before PND 21) when many of the deep-located neurons (the later-born subpopulation of the early postmitotic neurons) either die or change their midbrain projection profiles. Inoue et al. (1991) showed in reeler that corticospinal neurons initially are spread across the radial axis of developing cortex and that in the adult reeler a loss of retrogradely labeled corticospinal neurons occurs in the deep portion of the cortex. Analyses of both our BrDU and true blue labeling counts (which label overlapping but not identical populations) suggest that the loss of corticospinal neurons in the deep cortex is due to cell death and axon retraction. Some neurons in the deep half of the reeler cortex that were labeled by true blue cerebral peduncle injections on PND 2 were still present on PND 21 when cerebral peduncle injections of true blue into reeler mice fail to label any deep neurons, suggesting that some of the loss within the deep cortex may be due to axon retraction. In murine development the functional maturation of many cortical systems is due to the retraction of axons and axon collaterals that occurs during the first 2 postnatal weeks (Innocenti, 1981; Ivy and Killackey, 1982; O'Leary and Stanfield, 1985, 1989; Stanfield and O'Leary, 1985).

The apparently inverted adult reeler cortex may result partially from a late postnatal cell death and axon retraction of neurons located in the deep cortex produced by the strong canalizing effect of activity-dependent afferent mechanisms. Cortical afferents project and synapse on presumptive subplate and early postmitotic presumptive deep-layer neurons (Shatz ct al., 1990; De Carlos and O'Leary, 1992); however, in the reeler these neurons are primarily ectopically positioned at the top of the cortex, and thus thalamic axons project superficially (Caviness and Frost, 1983; Molnar and Blakemore, 1992). Neuronal perikarya within superficial reeler cortex survive and maintain projections to the midbrain, but projection neurons in the deep reeler cortex die or retract their axons, perhaps because they fail to capture afferent connections. Our evidence suggests that the reeler mutation primarily acts upon a subpopulation of the earliest postmitotic deep-layer cortical neurons, causing them to be hypermorphically adhesive, resulting in the early split of deeplayer-fated neurons into deep and superficial positions.

\section{References}

Abercrombie M (1946) Estimation of nuclear population from microtome sections. Anat Rec 94:239-247.

Angevine JBJ, Sidman RL (1961) Autoradiographic study of cell migration during histogenesis of cerebral cortex in the mouse. Nature 192:766-768.

Bayer SA, Altman J (1990) Development of layer I and the subplate in the rat neocortex. Exp Neurol 107:48-62.

Caviness VS (1982) Neocortical histogenesis in normal and reeler mice: a developmental study based upon $\left[{ }^{3} \mathrm{H}\right]$ thymidine autoradiography. Dev Brain Res 4:293-302.

Caviness VS, Frost DO (1983) Thalamocortical projections in the reeler mutant mouse. J Comp Neurol 219:182-202.

Caviness VS, Rakic P (1978) Mechanisms of cortical development: a view from mutations in mice. Annu Rev Neurosci 1:297-326.
Caviness VS, Sidman RL (1973) Time of origin of corresponding cell classes in the cerebral cortex of normal and reeler mutant mice: an autoradiographic analysis. J Comp Neurol 148:141-152.

Clark PJ, Evans FC (1954) Distance to nearest neighbor as a measure of spatial relationships in populations. Ecology 35:445-453.

Crandall J, Caviness VS (1991) MAP2-immunoreactive neurites of preplate neurons in reeler mutant embryonic cortex. Soc Neurosci Abstr $17: 305.15$

Crandall J, Herrup K (1990) Patterns of cell lineage in the cerebral cortex reveal evidence for developmental boundaries. Exp Neurol 109:131-139.

Das GD (1979) Gliogenesis and ependymogenesis during embryonic development of the rat. J Neurol Sci 43:193-204.

De Carlos JA, O'Leary DDM (1992) Growth and targeting of subplate axons and establishment of major cortical pathways. J Neurosci 12: 1194-1211.

De Long GR, Sidman RL (1970) Alignment deficit of reaggregating cells in cultures of developing brains of reeler mutant mice. Dev Biol 22:584-600.

Drager UC (1976) Reeler mutant mice: physiology in primary visual cortex. Exp Brain Res [Suppl] 1:274-276.

Drager UC (1981) Observations on the organization of the visual cortex in the reeler mouse. J Comp Neurol 201:555-570.

Falconer D (1951) Two new mutants, "trembler" and "reeler", with neurological actions in the house mouse. J Genet 50:192-201.

Fishell G, van der Kooy D (1987) Pattern formation in the striatum: developmental changes in the distribution of striatonigral neurons. $\mathbf{J}$ Neurosci 7:1969-1978.

Fishell G, Rossant J, van der Kooy D (1990) Neuronal lineages in chimeric mouse forebrain are segregated between compartments and in the rostrocaudal and radial planes. Dev Biol 141:70-83.

Gage FH, Batchelor P, Chen KS, Chin D, Higgens GA, Koh S, Deputy S, Rosenburg MB, Fischer W, Bjorklund A (1989) NGF receptor reexpression and NGF-mediated cholinergic neuronal hypertrophy in the damaged adult neostriatum. Neuron 2:1177-1184.

Garber BB, Huttenlocker PR, Larramendi LMM (1980) Self-assembly of cortical plate cells in vitro within embryonic mouse cerebral aggrcgates. Golgi and clectron microscopic analysis. Brain Res 201: 255-278.

Goffinet AM (1979) An early developmental defect in the cerebral cortex of the reeler mouse. Anat Embryol (Berl) 157:205-216.

Goffinet AM (1984) Events governing organization of postmigratory neurons: studies on brain development in normal and reeler mice. Brain Res Rev 7:261-296.

Goffinet AM (1992) The reeler gene: a clue to brain development and evolution. Int J Dev Biol 36:101-107.

Heckroth JA, Goldowitz D, Eisenman LM (1989) Purkinje cell reduction in the reeler mutant mouse: a quantitative immunohistochemical study. J Comp Neurol 279:546-555.

Innocenti $G$ (1981) Growth and reshaping of axons in the establishment of visual callosal connections. Science 212:824-827.

Inoue K, Terashima T, Inoue Y (1991) The intracortical position of pyramidal tract neurons in the adult motor cortex of the reeler changes from postnatal day 10 to adulthood. Dev Brain Res 62:146150.

Ivy GO, Killackey HP (1982) Ontogenetic changes in the projections of neocortical neurons. J Neurosci 2:735-743.

Johnston JG, Gerfen CR, Haber SN, van der Kooy D (1990) Mechanisms of striatal pattern formation: conservation of mammalian compartmentalization. Dev Brain Res 57:93-102.

Konig N, Marty R (1981) Early neurogenesis and synaptogenesis in cerebral cortex. Bibl Anat 19:152-160.

Krushel LA, van der Kooy D (1993) Pattern formation in the developing mammalian forebrain: selective adhesion of early but not late postmitotic cortical and striatal neurons within forebrain reaggregate cultures. Dev Biol 18:145-162.

Krushel LA, Connolly JA, van der Kooy D (1989) Pattern formation in the mammalian forebrain: patch neurons from the rat striatum selectively reassociate in vitro. Dev Brain Res 47:137-142.

Krushel LA, Johnston JG, Fishell G, Tibshirani R, van der Kooy D (1993) Spatially localized neuronal cell lineages in the developing mammalian forebrain. Neuroscience 53:1035-1047.

Lendahl U, Zimmerman LB, McKay RDG (1990) CNS stem cells express a new class of intermediate filament protein. Cell 60:585-595. Luskin M, Shatz C (1985) Studies of the earliest generated cells of the 
cat's visual cortex: cogeneration of subplate and marginal zones. J Neurosci 5:1062-1075.

Marin-Padilla M (1978) Dual origin of the mammalian neocortex and evolution of the cortical plate. Anat Embryol (Berl) 152:109-126.

McConnell S, Kaznowski C (1991) Cell cycle dependence of laminar determination in developing neocortex. Science 254:282-285.

McConnell S, Ghosh A, Shatz C (1994) Subplate pioneers and the formation of descending connections from. J Neurosci 14:1892-1907.

Miyatani S, Copeland NG, Gilbert DJ, Jenkins NA, Takeichi M (1992) Genomic structure and chromosomal mapping of mouse $\mathrm{N}$-cadherin gene. Proc Natl Acad Sci USA 89:8443-8447.

Miller MW, Nowakowski RS (1988) Use of bromodeoxyuridine-immunohistochemistry to examine the proliferation, migration and time of origin of cells in the central nervous system. Brain Res 457:4452.

Molnar Z, Blakemore C (1992) How are thalamocortical axons guided in the reeler mouse? Soc Neurosci Abstr 18:778.

O'Leary D, Stanfield B (1985) Occipital cortical neurons with transient pyramidal tract axons extend and maintain collaterals to subcortical but not intracortical targets. Brain Res 336:326-333.

O'Leary D, Stanfield B (1989) Selective elimination of extended axons by developing cortical neurons is dependent on regional locale: experiments utilizing fetal cortical transplants. J Neurosci 9:2230-2246.

Pinto-Lord M, Evrard P, Caviness VS (1982) Obstructed neuronal migration along radial glial fibers in the neocortex of the reeler mouse: a Golgi-EM analysis. Dev Brain Res 4:379-393.

Raedler E, Raedler A (1978) Autoradiographic study of early neurogenesis in rat neocortex. Anat Embryol (Berl) 154:267-284.

Redies C, Takeichi M (1993) Expression of N-cadherin mRNA during development of the mouse brain. Dev Dynam 197:26-39.
Seeds N (1983) Neuronal differentiation in reaggregate cell cultures. In: Advances in cellular neurobiology (Moscona AA, ed), pp 57-79. New York: Academic.

Shatz CJ, Ghosh A, McConnell SK, Allendoerfer KL, Friauf E, Antonini A (1990) Pioneer neurons and target selection in cerebral cortical development. Cold Spring Harbor Symp Quant Biol 55:469-480.

Shur BD (1982) Galactosyltransferase defects in reeler mouse brains. J Neurochem 39:201-210.

Sidman RL (1968) Development of interneuronal connections in brains of mutant mice. In: Physiological and biochemical aspects of nervous integration (Carlson FD, ed), pp 163-193. Englewood Cliffs, NJ: Prentice-Hall

Smart IHM, Smart M (1982) Growth patterns in the lateral wall of the mouse telencephalon: autoradiographic studies of the histogenesis of the isocortex and adjacent areas. J Anat 134:273-298.

Stanficld B, O'Leary D (1985) The transient corticospinal projection from the occipital cortex during the postnatal development of rat. $J$ Comp Neurol 238:236-248.

Steinberg MS (1970) Does differential adhesion govern selfassembly processes in histogenesis? Equilibrium configurations and the emergence of a hierarchy among populations of embryonic cells. $J$ Exp Zool 173:395-434.

Takahashi T, Nowakowski RS, Caviness VS (1992) BUdR as an S-phase marker for quantitative studies of cytokinetic behavior in the murine cerebral ventricular zone. J Neurocytol 21:185-197.

van der Kooy D (1992) Neocortex development and the cell cycle. Science 256:849.

van der Kooy D, Fishell G (1987) Neuronal birthdate underlies the development of striatal compartments. Brain Res 401:155-161. 